within the limits of the variations in blood pressure, that it is only late in life or in consequence of serious disease and overstraining that a slight stretching can be made out, $\mathrm{s}$ the form of a very slcwly progressive dilatation of the arterial system. The arteries of the dead body behave differently even immediately after death. If the pressure within them be temporarily raised to the height of the normal blood pressure they never perfectly return to their original width and thus manifest a certain loss of elastic quality due to the cessation of nutrition and innervation. Their elasticity has become less perfect, but this loss of elastic quality which occurs after death need not be considered in dealing with living arteries. Indeed, it has been usually disrezarded for this reason, even by those authors who have noted it in their measurements. Gibson is therefore wrong when he says of Roy's experiments: "In all these experiments the extent of distortion from which there was perfect restoration to previous form and bulk has been correctly taken as the measure of the amount of elasticity." The words "from which there was perfect restoration to previous form and bulk" cannot, as we have just seen, correctly be inserted here and were never employed by Roy. Their omission would give the sentence a very different meaning.

The limit of resistance to rupture in the vessel walls is also of some importance. A normal artery can withstand an internal pressure of several atmospheres, while under pathologival conditions the increase of distensibility of the vessel wall is accompanied by a great lowering of the limit of resistance to rupture. The artery may then rupture with an internal pressure of from sixteen to thirty centimetres of mercury. This is of great importance in relation to the forma. tion of aneurysms, but is of less value for the questions here discussed. These considerations have led all writers who have studied the elasticity of the walls of arteries and other tissues in man and animals to regard the ratio between stress and strain as the essential point, whether they, like Roy, determined the variations of cubic space within the arterias at different pressures of their contents, or, like my. self, o'sserved the variations in the lir ear dimensions of the vessel-wall. In this instance Weber ${ }^{7}$ and $W_{\circ}$ rtheim ${ }^{8}$ arrived at a result of general inportanc'. They stated that for organic tissues the ratio between stress and stain is not constant, the strain growing much slower than the stress, the curve of distension being very nearly a hyperbole.

The ratio between stress and strain, besides being the main object of our experimental investigation, yields us also the measure for the elastic properties of the vessel wall. If an artery shoxs greater distensibility within the limits of its elastioity to a given blood pressure Roy and Gibson regard $t$ as more elastic, thus using the word in its popular sense, according to which distensibility is the most important property in the elasticity of a body. Hermann, ${ }^{9}$ myself, and others, however, adopt the opposite acceptation, as I have stated definitely elsewhere 10 as follows: "Elasticity is a property of matter the measure of which is the amount of force which, during stretching, the particles of matter oppose to the change of their original equilibrium. I thus speak of iacreased elasticity when a greater force or a bigher blood pressure is required to distend the vessel wall to the same multiple of its linear dimension, and I consider those arteries f:ebly elastic in which the walls are relatively largely distended by slight stretching or by low blood pressure." This definition is also contained in the sentence quoted by Gibson from my text-book: "The elasticity of the ressel wall and therefore the resistance which it offers to stretching, \&." My use of the term also is in complete agreement with that of Fe'vin and Tait who state: "Hence the elastic quality of a perfectly elastic, homogeneous, isotropic solid is fully defined by two elements-its resistance to compression and its resistance to cisturtion." The amount of uniform pressure in all directions per unit area of its surface required to produce a stated very small compression measures the first of these and the amount of the shearing stress required to produce a stated amount of shear measures the second. The numerical measure of the first is the compressing pressure divided by the diminution of the bulk of a portion of the substance which when uncompressed occupies the unit volume. It is sometimes called the elasticity of volume, or

M. Weber : Priggendor fi's Annalen, vol. liv.

8 Wertheim: Annales de Chmie et de Pbysique, série iii,, rol. xxi., 1847

Hermann: Handbush der Physiologie, vol 4., i , p. 7., Leipzig, 1879.

10 Thoma: Ueber die Elasticitit der Netzhautarterien; v. Graefe's Archiv fur Ophthalmologie, vol. xxxv. the resistance to compression, or the modulus of compression. The second, the resistance to change of shape, is measured by the tangential stress divided by the amount of distortion or shear which it produces, and is calle? iive modulus of rigidity, or for brevity, rigidity, of the substance, or its elasticity of figure."

It is quite clear that the difference between the use made by Roy and Gibson of the word "elasticity" and the use which I have made of it depends merely upon an abbreviation of the expression, "ratio stress to strain." The question is, Which of these two abbreviations is the proper one? The use of the word "elasticity," preferred by Gibson and Roy, corresponds fairly closely with the popular meaning, whereas the sense in which I employ it is that ordinarily used by scientific men in explaining the nature of elasticity.

As regards the elasticity of the arteries there is stilk another fact to be considered. When the arterial walls are implicated in some general disturbance of metabolism or are subjected to over-exertion their distensibility under given alterations in blood pressure is increased-their resistance to stress is less. Gibson must term this shortly an increase of elasticity produced by morbid conditions, whereas I believe that the term diminution of elasticity is preferable, since not only the distensibility but also the tendency to rupture of the vessel wall is increased, and is in many cases combined with fatty degeneration of the walls.

I believe that I hare now sufficiently justified my opinion and do not consider it necessary to discuss the other items in Gibson's extraordinary paper, nor shall I touch upon the question of the retinal pulse, in regard to which Gibson betrays complete ignorance of the facts and of the investigations which I published on this subject in Von Graefe's Arehiv. I purposely abstain from expressing any opinion as to the manner in which Gibson has chosen to attack me, knowing that I may confidently leare this to the judgment of his fellow cuuntrymen.

Magdeturg.

\section{SEVENTEEN CASES OF DIPHTHERIA WITHOUT A DEATH--FIFTEEN TREATED BY ANTITOXIN.}

By J. RONALDSON RUSSELT, II R.C.S. ExG., L.R.C.P. LOND., AND

ARTHUR MALDE, M.R.C.S. ENG., L R.C.P. LOND., L.S.A.

THE following cases occurred in our practice during the present year; a few of them we bave cast for convenience in a tabular form.

CASE 1.-A girl nine Jears of age began to ail on Feb. 14th and on the following day complained of sorethroat. On the $17 \mathrm{ch}$, when the child was first seen, the breathing was rapid, being mainly through the mouth. The patient did not seem to be very ill; the temperature was $99^{\circ} \mathrm{F}$. and the pulse was 112 and fairly good. Both tonsils were much enlarged and were completely covered with membrane. A small patch which was on the palatal arch was like washleather in appearance; 10 c.c. of antitoxin were injected. On the 18 th the temperature was $101^{\circ}$ and the pulie was 104 and fairly good. The membrane had extended half over the palate; 10 c.c. of antitoxin were administered at $6.45 \mathrm{P}$.M. The membrane in the throat bad become more extensive. The temperature was $100^{\circ}$ and the pulse was gocd, being 112 . On the 19th the child was not so well. The breathing was entirely cral. A good deal of thick purulent discharge came from the posterior nares. The membrane was more extensive. A good amount of urine was passed, and it contained no albumin; 10 c.c. of antitoxin were injected in the evening. On the 20 th the patient was much better; there was less membrane, and what remained was loose. On the 21 st the child was very well. The throat was quite clear. The urine was abundant and it contained no albumin. The temperature was normal. On the 22nd tingling in the left foot was complained of ; the left patellar reflex was less marked than the right. The throat was clear and the pulse was 68 and very irregular. On the 24th the temperature was normal and the child felt well; the pulse was steady and numbered 54. An urticarial rash over the arms and legs bad appeared; on tle 
following day the rash was fading. On the 29 th there had developed what appeared to be an attack of acute rheumatism ; the knees were principally affected. The temperature was slightly elevated. Sodium salicylate was given and the attack passed off in two or three days. On March 8 th the patient seemed to be quite well; the reflexes were present. There was no albuminuria and the urine was abundant. Slight chronic enlargement of the tonsils was present. On April 5th the child was in perfect health and was so on Oct. 15th.

CASE 2.-This patient, who was not treated by antitoxin, was an unmarried woman aged twenty-two years. On Feb. 15th she went to stay in an infected house. On the 17th her throat felt sore. On the $19 \mathrm{th}$ she had shivering, fever (teinperature $101^{\circ} \mathrm{F}$.), and vomiting. There were diphtheritic patches on both tonsils. A gargle of hydrargyri perchloridium ( 1 in 1000) was ordered to be used constantly. On the 20 th the temperature was normal and the patient felt better. The throat was more comfortable, and there was less membrane. On the 2lst the patient felt quite well. The temperature was normal. There was no membrane. On March 8th there was no return of membrane and no sequelæ.

CASE 3.-The patient was a girl aged one year and a half. She had been ailing for some days with catarrh (nasal and bronchial). On Feb. 23rd the nose and throat were much stuffed up. The throat was completely full of membrane and purulent matter. The membrane extended to the tip of the tongue. The child was very ill. 10 c.c. of antitoxin were injected at $11.30 \mathrm{~A} . \mathrm{M}$. In the evening she was no better. Respiration was laboured and she was ordered a carbolic steam kettle. On the 24 th the patient was much worse and she had laryngeal stridor. In the evening the stridor was more pronounced There was slight recession of intercostal spaces and slight cyanosis. The throat was much clearer. The temperature was normal, 5 c.c. of antitoxin were injected. On the 25 th the breathing was worse during the night; stridor was very marked in the morning. There were jactitation, cyan ssis, and marked recession of interspaces. Chloroform was administered and tracheotomy performed with difficulty. Parker's tube was ins $\leq r t e d$. The child was pulseless and respiration ceased. Restoratives were administered. The temperature at $10 \mathrm{P} \mathrm{M}$. was $103.4^{\circ} \mathrm{F}$. On the 26 th the child breathed much more freely since the operation and had taken food better. The tube was removed constantly. There was thick muco-purulent discharge coming from tine lungs. On the 27 th the cough had been very troublesome and the tube was constantly blocked. There was not much membrane visible in the throat. On the 28 th the child was very sick and restless. On the 29 th she was in statu quo. On March 1st the child vomited all her food, but peptonised foods were retained. The tracheotomy tube was left out; the child breathed better without it. On the $20 d$ the patient had a very restiess night. On the 3rd there was a good deal of diarrhoea. The tracheotomy wound looked rather inflamed and was dischargirg pus. It was dressed with cyanide gauze soaked in eucalyptol every half hour. On the 7th the patient was taking food well. The cough and discharge ceased. The trachea wound was quite clo.ed and granulating healthily on the surface. The child was quite herself and playing about. On the 10 th the patellat reflexes were absent She would not take anything of a sloppy nature, as fluids regurgitated through the nose. There was incontinence of urine. She was taking food well and putting on flesh. On the 12 th the regurgitation was not so marked. Breathing was not so good. The pulse was 120 , irregular, but fairly good. On the 17th breathing was normal. On the 31 st the patellar reflexes were still absent. There was no regurgitation. The child could not stand at all. The incontinence continued, but the general condition was good. On April 3rd she had a sharp attack of diarrhcea, but was well on the 5th. On the 7 th the patient was sent away. She was seen a month after and was then quite well. The voice was still rather husky.

CASE 4.-The patient was a girl aged two and a half years. On March 11th she was sejzed with vomiting. The temperature was $101 \cdot 6^{\circ} \mathrm{F}$. The pulse was 164 and weak. There was a small, thin, diphtheritic patch on the left tonsil; 10 c.c. of antitoxin were injected at $11 \mathrm{~A} . \mathrm{M}$. On the 12 th the child was taking food well. The membrane on both tonsils was thicker, but loose at the edges. The temperature was normal. There was incontinence of urine. On the 13th the child was taking food well. The temperature was normal. The throat was much clearer. Only[a small piece of membrane remained hanging. The incontinence continutd. On the 15 th the throat was quite clear. There was no incontinence. The patellar reflexes were absent. On the 17 th the patient was improving. There was regurgitation of fluids through the nose and the voice was becoming nasal. There were no reflezes. On April 3rd the swallowing and voice were normal. She had an attack of diarrhoea. The temperature was $101^{\circ}$. There was blood in the motions. On the 5 th the diarrhoea yielded to treatment. On the 7th the child was sent away for a change, and when seen a month later was quite well.

CASE 5.-Male aged seren wetks. On Jan. 8th he had been ailing all day. In the evening symmetrical patches of white, firmly aỏherent membrane were seen on both tonsils. The temperature was normal and the pulse poor. The fontanelle was much depressed. 8 c.c. of antitoxin were injected at 7 P.M. and brandy was ordered. On the 9 th the child was much better and was taking food well. The throat was clearer. On the 10 th he was improving. The throat was almost clear. On the 11th he was doing well. The throat was quite clear. On the 29 th he was quite well. He had had no signs of neuritis or albuminuria and was putting on flesh rapidly. On March 8 th he remained well.

CASE 6. - The patient was a woman aged thirty-two years. On Jan. 5th her throat was rather tender and swollen. On the 6th she felt chilly. There was no rigor. The temperature was $100.8^{\circ} \mathrm{F}$. There was a small diphtheritic patch on each tonsil. At $10.30 \mathrm{~A} . \mathrm{M}$. $15 \mathrm{c.c}$. of antitoxin were injected. At 4.30 P.M. the temperature was $102.2^{\circ}$; the pulse was good (124). On the 7th the temperature was $1012^{\circ}$ and the pulse was 120 . In the throat the membrane was more extensive, involving almost the whole of both tonsils, but seemed looser; the patient had expectorated one piece of membrane. The urine was abundant; there was no albumin. She felt much better. At 7.20 P.M. mire membrane was expectorated. On the 8th the temperature was normal and the throat was almost clear. Swallowing was much easier. The patient said that her throat was more comfortable than it had been for years. The right patellar reflex was absent. On the 9 th the throat was much clearer and more comfortable. There were no reflexes. The urine was abundant; there was no albumin. On the 10th the temperature was normal; the throat was quite clear and there were no reflexes On the 19th the patient had an attack resembling asute rheumatism, with pains in every part of the body. The temperature was $99^{\circ}$ and there were slight reflexes. On the $22 n$ a the patient had an acute rheumatic attack. The temperature was $99^{\circ}$. Sulicylate of soda and bicarbonate of potas $h$ were ordered. The rheumatic pains continued until the $26 \mathrm{th}$ and the temperature rose to over $100^{\circ}$. An urticarial rash appeared all over the chest; there was no swelling of the joints. By the 28th the rash had disappeared, the temperature was $99^{\circ}$, there was no pain, and the patient felt very well. On Feb. 19th a patch of what appaared to be diphtheritic membrane was seen on each tonsil. A gargle of perchloride of mercury ( 1 in 1000) was given. On the 2lst the throat was found to be clear; and on March 8 th the patient was quite well and there had been no sequelæ.

CASE 7.-A female child aged three y ears and nine months, who had been ailing sicce the previous day. In the evening of Nov. 25th, 1895, she complained of sore-throat. The mother said that the glands av the angles of the jaw were swollen and tender, but that she could see nothing wrong in the throat. The patient slept well at night. On the $26 \mathrm{th}$ the mother saw membrane on the tonsils. I saw the child whose temperature was $1005^{\circ} \mathrm{F}$. and the pulse was rapid and fairly good. The uvula and the adjacent parts of the palate and both tonsils were covered with white, tough, firmly adherent membrane. The glands at the angle of the jaw were swollen and tender. At 330 P M. 10 c.c. of antitoxin were injected. The consequent swelling soon subsided. At 9 P.M. the temperature was $101^{\circ}$. The throat was clearer and the membrane looked thinner. The respiration was very snoring in character, not laryngeal. A mixture containing borax and iron was given every four hours and brandy was administered. On the 27 th at $1030 \mathrm{A.M}$. the temperature was $101^{\circ}$; the pulse 160 , weak and compressible; and the child had a bad night and seemed worse. The throat was clearer and the membrane looser, but none had separated. The respiration was very rattling through nasal obstruction. There was no dyspncea. Brandy and a steam-kettle containing carbolic acid were ordered. 
Table of Eight Remaining Casms in Seventeen Cases of Dipmtheria without a Death.

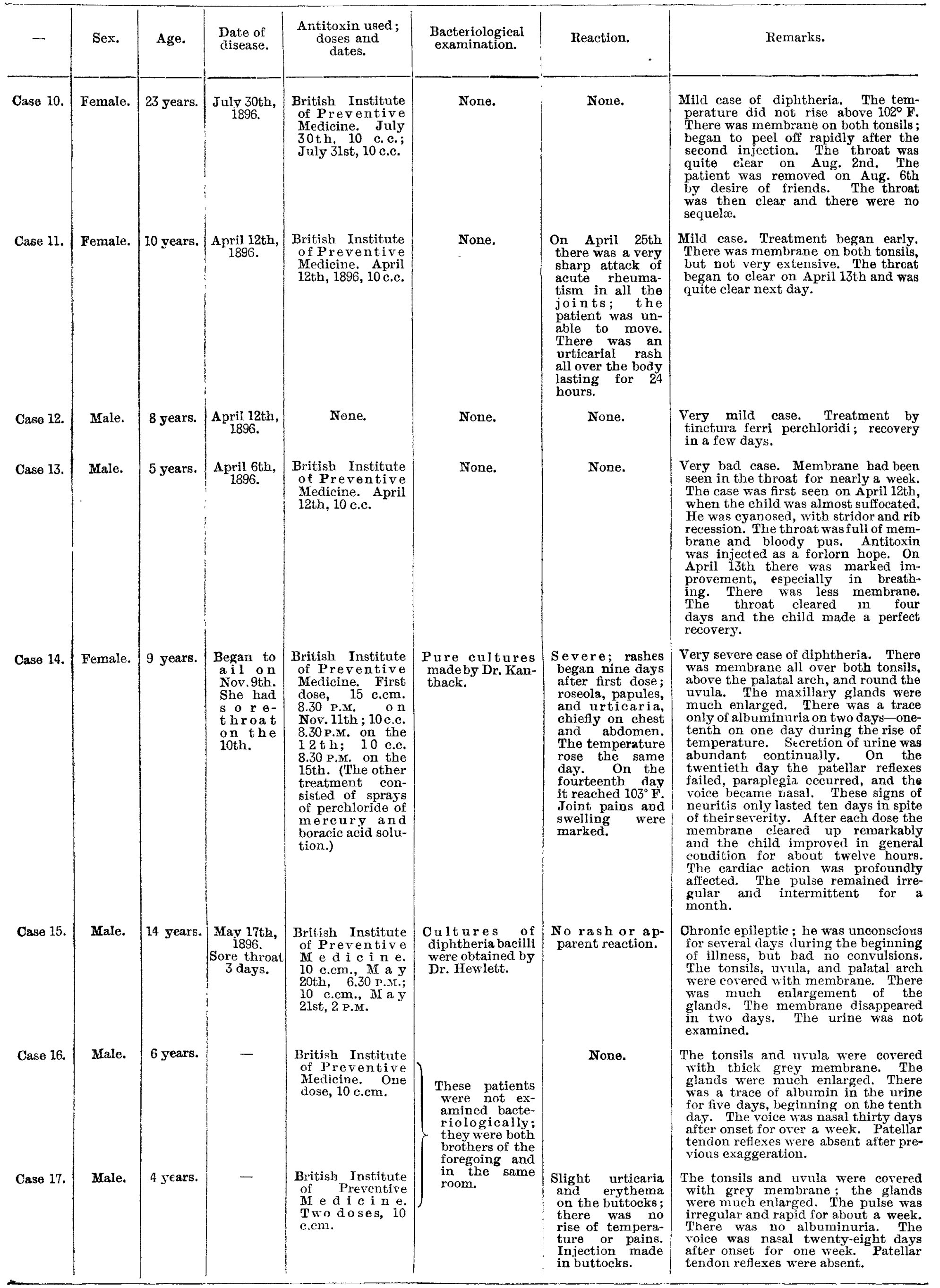


At 7 P.M. the temperature was $101^{\circ}$ and the pulse was stronger (140). The throat was full of membrane. Valentine's meat juice and brandy were given as before. The child slept well. The bowels had not acted since the onset. The child had not complained much of her throat. On the 28th the temperature was $101^{\circ}$ and the pulse was stronger (160). The same regions in the throat were covered with membrane, which was thicker and firmer, and the throat was full of sanious purulent matter, which appeared to come from the posterior nares. Respiration was about the same; there was no discharge from the anterior nares. The patient had taken nothing all night. At noon 10 c.c. of antitoxin were injected followed by some local swellings. The child complained of a pricking. At 7 P.M. the temperature was $101 \cdot 8^{\circ}$ and the pulse improved in tone (144). The aspect of the case had improved; the patient had taken milk (half a pint with brandy as before since morning). The membrane in the throat was thicker than before. There was no laryngeal involvement. She was worse during the night, but on the following morning (the 29th) at 10.30 A.M. looked more herself. The respiration was quieter and the bowels had acted freely. The temperature was $99.8^{\circ}$ and the pulse 132 . There was the same amount of membrane in the throat, which had become very white and was getting loose at the margins. There was a large slough on the uvula. At 7 P.M. 10 c.c. of antitoxin were injected, and were followed by pain over the cardiac region, but there were no physical signs. The temperature and pulse were the same as in the morning. On the 30th the child was much worse; she had taken nothing during the night. The temperature was $998^{\circ}$; the pulse was 140 , very weak, and compressible. The throat was about the same. Brandy was administered every hour with Valentine's meat juice. At 7 P.M. the child was brighter, had a better colour, and had played with toys. The temperature was $99.6^{\circ}$ and the pulse was much stronger (120). In the throat there was the same amount of membrane, which looked like separating. The respiration was quiet and normal. The bowels acted well; the glands were subsiding and less tender, and the patient passed plenty of urine. She passed a good night. On Dec. 1st, at 11 A.M., the temperature was normal, the pulse 120, and the respiration was very slow, but there was no embarrassment or obstruction in the nose. The throat was very much clearer, and a good deal of membrane had separated, leaving a dirty brown sloughy surface. On the 2 nd the temperature was $99^{\circ}$, the throat was almost clear, and the urine contained a good deal of albumin. On the 3rd the throat was quite clear, about five ounces of urine were passed in twenty-four hours, and there was less albumin. On the following day the patient remained the same. On the 5th fifteen ounces of urine (half albumin) were passed in twenty-four hours; and on the 6th and 7 th the urine was less in amount, but there was more albumin. On the 8th two ounces of urine were passed in twenty-four hours, being very thick with albumin; on the 9th half a pint was passed with less albumin; and on the 10th three-quarters of a pint in twenty-four hours, but no albumin. On the 11th, 12th, and 13 th the urine measured about one pint in twenty-four hours and was normal. On the 19th the child seemed very lively and well. The heart had become very irregular, but there was no bruit. The patellar reflexes were absent. The temperature had been normal since the 3rd. On Feb. 22nd, 1896, the child suddenly complained of sore-throat, vomited, and refused food. The temperature was raised. Both tonsils were covered with membrane, which had the same appearance as at the first onset. She was treated with perchloride of iron in five-minim doses every two hours and a spray of perchloride of mercury and water (equal parts). On the 25th the throat was quite clear and the child was perfectly well; and she was doing well when seen at the end of March.

CASE 8.-A boy aged four years. On Dec. 28th, 1895, he had been ailing all day; he was feverish, but he had not vomited. A calomel powder was administered. On the following day he complained of sore-throat; the bowels had acted. On the 31 st the throat was worse. When seen in the evening the temperature was $99.2^{\circ} \mathrm{F}$. and the pulse was 120 and very good. The respiration was entirely oral, there being nasal obstruction. Both tonsils were completely covered with thick, grey membrane. 10 c.c. of antitoxin were administered. On Jan. 1st, 1896, the child was not so well. In the throat the membrane was thicker and more extensive. There was no laryngeal involvement. 10 c.c. of antitoxin were administered at 9 P.M. On the 2nd he was better ; the temperature was normal and the pulse was $90^{\circ}$. The throat was clearer. Oñ the 3 rd the condition had improved; the throat was almost clear and the glands were subsiding; in the evening the throat was quite clear and the condition much improved. The improvement continued until the 7th, when the patellar reflexes were absent and albumin appeared in the urine. The temperature had not been above $99^{\circ}$ since the 3rd. On the 8 th the temperature and pulse were normal. No reflexes were present. The urine was abundant and contained less albumin. On the 9th he passed less urine and there was still slight albuminuria. The mother said that his voice had become quite like a girl's and weaker. On the following day the right patellar reflex was returning. On the 14th the voice had become more normal and on the $17 \mathrm{th}$ it was quite nasal ; swallowing was good on the latter date. On the 19 th no refiexes were present; the voice was very nasal. His mother said that he took much longer to drink anything than he did formerly. On the 22 nd the voice sounded as if the boy had a cleft palate. There was slight regurgitation of fluids through the nose. On the 26 th the voice was more normal and there was not so much regurgitation; the pulse was 140 . On the 29 th the reflexes were gradually returning. The boy was very well and ate heartily. On March 8 th the voice was normal and no regurgitation was present. The legs were still rather weak and the gait was awkward, but otherwise he was quite well. He was sent to the seaside and made a perfect recovery.

CASE 9. - This patient, who was not treated by antitoxin, was a boy aged thirteen years the subject of old infantile paralysis. On May 29th dirty ash-coloured membrane was seen on the tonsils and uvula. He had been ill four days and his case was considered too late for antitoxin. The treatment consisted of frequent swabbing of the fauces with perchloride of mercury solution and boracic acid gargles. On the 31 st the membrane was found to be clearing. On June 2nd the patient had several fainting attacks and attacks of dyspnoea. The pulse was very slow, 48, and irregular. Breathing was very slow. The urine was very scanty for several days (once only $4 \mathrm{oz}$. in twenty-four hours), but no albumimuria was noted. In the third week he was quite paraplegic for about a week. There was complete absence of knee-jerks. There were no palate symptoms. Complete recovery ensued within six weeks.

Remarks by Mr. Russtel. - The antitoxin used was obtained from the Bitish Institute of Preventive Medicine. In all the cases examined pure cultures of bacillus diphtheria were obtained by Dr. Hewlett. The diagnosis was verified in Cases 1, 6, 7, and 8. The injection was made under the skin over the ribs with antiseptic precautions, and in no case was there any sign of local inflammation. Cases 1 and 4 complained of a good deal of pain at the site of injection for some hours afterwards. The patients in Cases 1, 3 , 5 , and 8 were all children of the patient in Case 6 and occupied the same room. Case 5 was weaned directly the mother fell ill with the disease. The patient in Case 2 (sister of the patient in Case 6) was also in the house. Cases 11,12 , and 13 occurred in one house, all the children occupying the same room and were undoubtedly cases of diphtheria, as was Case 10, though the diagnosis was not verified.

Remarks by Mr. MAUDE. - Several of these cases were of exceptional severity, particularly Case 14. The later cases, under both Mr. Russell and myself, were milder in type. In Case 14 the symptoms were severe, the dose of antitoxin was large, the reaction was severe, and the diphtherial neuritis was very profound and widespread, but it was also very short. She had also marked clonic twitching of the limbs for two days. Goodall has remarked that this condition may occur independently of severe albuminuria, as in this case; it is a symptom of grave augury. The exaggerated knee-jerk which Herringham pointed out some years ago as the precursor of its disappearance was noted in one case. Seventeen cases of diphtheria without a death, one case being seven weeks old, is a gratifying record.

Westerham.

Grosvenor Hospital For WoMen AND ChILdRen. The Grosvenor Hospital for Women and Children, Vincentsquare, Westminster, has received twenty guineas from the Merchant Taylors' Company. 